CASE STUDY

\title{
Research Assistant as Partner: Collective Leadership to Facilitate Co- production
}

\author{
*Joshua Timothy Hill, Christy Thomas, and Barbara Brown, University of Calgary, Calgary, \\ Alberta, Canada
}

Contact: joshua.hill@ucalgary.ca

\section{ABSTRACT}

In this article, we chronicle our experience of student-faculty partnership within a Scholarship of Teaching and Learning design-based research study. We present our experience of partnership in relation to the student-faculty partnership, collective leadership, adult learning and knowledge building literatures. Key characteristics of our student-faculty partnership are recognizing and using intellectual and experiential resources; practicing principles of knowledge building; and differentiating top-down and lateral decision making. We find the affordances of our partnership to be increased productivity, learning from each other and diversity of ideas and perspectives and limitations to be substantial time commitment, underlying beliefs about students' capabilities and student-faculty ratio to limitations. We conclude by exploring the impact of our partnership on students, faculty and the university.

\section{KEYWORDS}

student-faculty partnership, Students as Partners, design-based research, collective leadership, Scholarship of Teaching and Learning

The prevailing conceptualization of the role of the student in higher education is that of student as consumer in a marketplace, a conceptualization that de-emphasizes the student's role in the process of learning (McCulloch, 2009). Students as Partners (SaP), that positions faculty and students as partners in teaching and learning, has emerged as an alternative conceptualization (Cliffe et al., 2017). Research in this field is gaining prominence and recent studies have demonstrated the beneficial outcomes of faculty engaging with students in partnership; therefore, we need to continue to build on this foundation and explore new directions to enrich teaching and learning in higher education (Mercer-Mapstone et al., 2017). Yet despite this promise and momentum, the "customs and culture of higher education often make it difficult for both students and staff to take on new roles and perspectives" (MercerMapstone et al., 2017, p. 2). 
In this article, we describe our experiences of fostering a student faculty partnership within the context of a design-based research study in which we investigated instructional design to support group work. Our research team culture was characterized by "respect, responsibility, and reciprocity" (Cook-Sather, Bovill, \& Felten, 2014, p. 6) and this allowed us to reframe the role of the student from that of student as consumer to student as co-producer of knowledge (McCulloch, 2009; Neary \& Winn, 2009). In the forthcoming sections we outline the context for our partnership, chronicle how we practiced principles of collective leadership within a design-based research approach, analyze the affordances and potential challenges associated with our implementation of a student-faculty partnership, consider the impacts of our partnership on the members of our team and the broader university community, and look ahead to future questions for inquiry.

\section{CONTEXT OF OUR PARTNERSHIP}

The context of our partnership was a design-based research (DBR) study in which Dr. Brown was the principal investigator, Dr. Thomas a co-investigator, and PhD student Joshua Hill was a research assistant. Our research team also included another faculty member and an undergraduate research assistant. The study was supported by a Scholarship of Teaching and Learning (SoTL) grant and was focused on improving student learning in group work assignments through iterative improvements to instructional design. Our research was situated within a larger team of instructors who taught 16 sections of over 500 pre-service teachers in the Interdisciplinary Learning course in the Bachelor of Education program. In this required course, undergraduate students work in groups ranging in size from three to six members to develop an interdisciplinary unit plan. Instructors support group work throughout the course by using a variety of strategies that include offering time during class for student collaboration and providing access to instructor expertise.

\section{Design-based research activities}

Our SoTL study focused on improving group work through iterative cycles of redesigning the course outline and assessment criteria. In the first year of our two-year study, we investigated the ways in which instructional strategies such as scaffolding, assessment tools, and participatory technologies supported group work. We collected data from students and instructors using surveys and interviews and analyzed these using two cycles of iterative thematic coding (Miles, Huberman, \& Saldana, 2014). In the first cycle, three members of the research team individually coded the open-ended responses from the survey data. They reviewed each response and assigned a descriptive code as a label. During this first cycle, we also reviewed the codes, sharpened definitions, and reconciled differences together, as a team.

Each researcher reviewed their first cycle codes and grouped descriptive codes into a smaller number of categories for the second cycle of coding. The categories listed as one-word or short phrases provided as summary of the emerging themes. We also listed a detailed explanation or definition for each category. This process of defining each of the categories allowed each researcher to conduct a second round of coding with the same dataset, but using a smaller number of categories. Next, we worked together to review categories, sharing 
commonalities and reassigning codes as needed. We then generated themes and illustrated them in infographics representing the findings.

We shared these infographics with the instructor team in the context of a professional learning workshop. During the workshop, we employed a design thinking process that helped instructors glean insights from the data and collaboratively generate ways to respond, both in the design of the course outline and in their own instructional practices. The ideas generated in this discussion resulted in changes to the assignment requirements and assessment criteria in the course outline that were implemented in the subsequent academic year.

\section{Co-production activities}

As a research team we engaged in co-production of knowledge (McCulloch, 2009) to move our research study forward. Our co-production activities included developing infographics to share our findings with the instructor team, developing and leading a design thinking professional learning process to build instructional design capacity and developing changes to the course outline and assessment criteria, sharing our research with conference participants, and sharing with a broader audience through publication (Hill, Thomas, \& Brown, 2018; Brown, Thomas, Hill, \& Alonzo-Yanez, 2019; Thomas, Brown, \& Hill, 2019).

\section{Unique characteristics of DBR that contributed to our partnership}

Design-based research (DBR) is "a systematic but flexible methodology aimed to improve educational practices through iterative analysis, design, development, and implementation, based on collaboration among researchers and practitioners in real-world settings, and leading to contextually-sensitive design principles and theories" (Wang \& Hannafin, 2005, p. 6). DBR offered a unique context for our partnership because it is collaborative, innovative, and emergent in nature (Barab \& Squire, 2004; McKenney \& Reeves, 2012). Within a DBR approach, researchers adjust course based on emerging insights and data (McKenney \& Reeves, 2012). The emergent nature of DBR required our team to be innovative and make decisions in response to the data to determine the next research steps. Each of the members of our team took leadership in different tasks of our project, informed by our expertise, experience, and learning goals (a theme that we will later explore in detail). It is important to note that a research approach with a more rigid and predefined research design may not have offered the same opportunities for the collective leadership that characterized our partnership.

\section{CHARACTERISTICS OF OUR PARTNERSHIP}

We did not explicitly draw on the collective leadership literature to design our work together; however, it offers a useful theoretical frame to explain the practice that sponsored the conditions for a partnership characterized by "respect, responsibility, and reciprocity" (Cook-Sather, Bovill, \& Felten, 2014, p. 6). Collective leadership challenges traditional notions of hierarchy and power imbalance, creating the conditions for collective agency (Harris \& Muijs, 2004). Kennedy, Deuel, Nelson and Slavit (2011) describe three attributes of collective leadership that were relevant to our experience: recognizing and using intellectual and experiential resources, building culture through dialogue and inquiry, and differentiating top- 
down and lateral decision making. In the following sections, we will chronicle our experiences of practicing collective leadership organized around these three attributes.

\section{Recognizing and using intellectual and experiential resources}

Each member of our research team brought forward and drew on our strengths and previous experiences. For example, Josh, our graduate research assistant, was able to draw on previous professional experience to initiate, design, and lead the design thinking professional learning session for our instructor team. Dr. Thomas, our co-investigator, drew on her experience employing mixed methods to lead the data analysis process (Thomas, 2016), and principal investigator Dr. Brown's research experiences employing mixed methods and research-practice partnerships guided how we shaped our partnership with our instructor team (Brown, Hartwell, \& Thomas, 2018; Brown \& Jacobsen, 2016.) Kennedy et al. (2011) suggest that establishing routines is important to facilitate collective leadership. In our experience, having regular team meetings was a key routine that moved our research work forward. In these meetings, we collaboratively designed the meeting agendas, each contributing openly, made decisions through seeking consensus and established action item lists. We used Google Drive and Outlook Calendar as collaborative tools to facilitate the organization and documentation of our team meetings.

\section{Practicing principles of knowledge building.}

Central to our team meetings was a culture of dialogue and inquiry. Our team's collaborative practices closely aligned with Scardamalia and Bereiter's (2006) principles of knowledge building. Important to our culture was treating all ideas as improvable, communally taking responsibility for the advancement of ideas, seeking to identify and address problems and gaps, and pursuing diversity of ideas. These practices aligned closely with our design-based research approach which, as we have previously described, called for iterations within the course of the research study and required us to constantly make sense of our emerging data to determine next steps.

\section{Differentiating top-down and lateral decision making}

As primary investigator, Dr. Brown held what could be considered a formal leadership position on our team. Collective leadership does not mean that no one is ultimately responsible within an organization but "rather, the job of those in formal leadership positions is primarily to hold the pieces of the organization together in a productive relationship" (Harris \& Muijs, 2004, p. 28). Dr. Brown created the conditions for recognizing and using intellectual and experiential resources and practicing dialogue and inquiry. She primarily did this through leading by example and encouraging the other team members to exercise their agency. Harris and Muijs caution against "misguided delegation," and in our partnership, Dr. Brown retained the responsibility for making decisions that could not be shared, such as the project setup, budget management, and hiring of the research assistants. 


\section{ANALYSIS OF OUR PARTNERSHIP}

In the following sections we offer an analysis of our experiences of the affordances and limitations of practicing collective leadership in student-faculty partnership.

\section{Affordances}

The three affordances of practicing collective leadership towards student-faculty partnerships that we identified from our experiences are increased productivity, learning from each other, and diversity of ideas and perspectives.

\section{Increased productivity}

A clear affordance of having each member of our team take responsibility for elements of the research project was the level of productivity this enabled. In a top-down team structure, the formal leader would spend time delegating, managing, training, directing, and reviewing the work of subordinates. In a collective leadership partnership, each member of the team is producing from an area of strength and experience. Our team meetings were characterized by knowledge building enabled by each member of the team coming prepared to share the work they had moved forward between meetings.

\section{Learning from each other}

A student-faculty partnership characterized by collective leadership activates the expertise and skills of all members of the team, providing opportunities for everyone to be both a teacher and a learner. Our experience of student-faculty partnership featured the following important conditions for adult learning that Merriam identifies (2008, p. 97-98): learner autonomy, reflection on learning, dialogue, active participation, and application of learning. The learning each of us engaged in was embedded in the development of our shared project and therefore always featured active participation and application of knowledge. For example, when we needed to share our research findings with our larger instructor team, Josh, our graduate research assistant, was able to draw on his experience leading collaborative design thinking protocols, and Drs. Thomas and Brown had the opportunity to learn alongside Josh in the design, implementation, and debrief of the instructor workshop.

\section{Diversity of ideas and perspectives}

Sustained knowledge creation depends on having access to diverse ideas (Scardamalia, \& Bereiter, 2003). As we have chronicled throughout this article, collective leadership promoted the conditions for all members of our research team to contribute ideas. Furthermore, bringing forward diverse viewpoints, particularly by including groups who are not in positions of power, provides new interpretations and offers perspectival knowing (Haraway, 1988). As a student and sessional instructor, Josh viewed the relevance and applicability of our research findings from a different perspective from those of Drs. Thomas and Brown. The collective leadership model of our partnership allowed for the student researcher perspective to influence the direction of our research. A tangible impact of this multiplicity of perspectives is evidenced in the diverse ways in which we shared the story of our research to different audiences through 
presentations and article submissions ((Hill, Thomas, \& Brown, 2018; Brown, Thomas, Hill, \& Alonzo-Yanez, 2019; Thomas, Brown, \& Hill, 2019).

\section{Limitations}

The three limitations of practicing collective leadership towards faculty student partnerships that we identified from our experiences were substantial time commitment, underlying beliefs about students' capabilities, and student-to-faculty ratio.

\section{Substantial time commitment}

We found that both faculty and students need to commit significant time to engage in a partnership characterized by collective leadership, and this is also reflected in the collective leadership literature (Harris \& Muijs, 2004). Adding to this challenge is the emergent nature of the responsibilities and commitments within this model. We were unable at the outset of this project to fully plan for the time we needed. This limitation is significant given the other commitments both students and faculty balance in the modern university (Berg \& Seeber, 2017).

\section{Underlying beliefs about students' capabilities}

The student-faculty partnership literature notes that student-faculty partnerships can be viewed as "troublesome, threatening, disappointing, and disruptive" and underpinned by the belief that students do not have the necessary understanding or experience to contribute alongside faculty members (Cook-Sather, 2014, p. 189). In our experience, partnership required the development of a relationship of trust and risk taking. This experience is underscored by the collective leadership literature that stresses the importance of building relationships when working together (Harris \& Muijs, 2004). We believe that our relationship of trust and risk taking was predicated on a shared belief that students can contribute as partners.

\section{Student-to-faculty ratio}

A student-faculty partnership enabled by collective leadership practice may not be scalable to teams with a larger student-to-faculty ratio. In our context, our primary team featured two faculty members and one student. We believe that it may not be possible in a large group for all members of the team to take leadership and responsibility to the extent Josh was able to in our study. As outlined previously Josh's expertise and experiences shaped the direction of our study in significant ways. We believe that if our team had included many students it may be difficult to find opportunities for leadership for all students.

\section{IMPACTS OF PARTNERSHIP}

In a review of Students as Partners research, Mercer-Mapstone et al. (2017) point out that the literature is predominantly focused on outcomes for students. To address this gap in the literature and to reflect on our experiences, we have identified benefits of a student-faculty partnership to the student, to faculty, and to the broader university community. 


\section{Impact on students}

Our student-faculty partnership provided the opportunity for Josh to shed the role of consumer to become a co-producer of knowledge. This experience served as excellent scaffolding to bridge between his PhD course work and his dissertation research project. The impact of partnership for him included: learning about conducting research through experience in all phases of a research project, learning about design-based research methodology, authoring and co-authoring multiple publications and presentations, and gaining insight into the expectations and opportunities of an academic career.

\section{Impact on faculty}

The student-faculty partnership offered a new faculty member, our co-investigator Dr. Thomas, the opportunity to be mentored by a more experienced faculty member, and in turn to mentor Josh in conducting research. The partnership also afforded further opportunities for Dr. Thomas to add to her scholarly contributions (i.e., publications and conference presentations) and get further experience in conducting design-based research. The value of the collective leadership model for Dr. Thomas' instructional practice is also evident in the expertise she gained from being exposed to Josh's design thinking processes and is applying to her leadership approach in future courses and research projects.

The partnership also impacted Dr. Brown in her role as the project lead. Providing mentorship to a graduate student Josh throughout the research process and responding to his questions helped Dr. Brown unpack the rationale for research design decisions, foundational literature and theoretical frameworks, methods of analysis, and how to use preliminary findings when making decisions about next steps in the research process. Involving Josh in team meetings as a co-producer led to extended dialogue and lengthier team meetings. This may be viewed as a limitation; however, the extended dialogue also led to increased idea generation and overall productivity. In our original research plan, the team planned for academic conference presentations and publications as methods of knowledge dissemination. The knowledge mobilization resources developed collaboratively by the team were strengthened by the added insights Josh provided. For example, he suggested we create infographics as a method to share our preliminary findings which made our research findings accessible to instructors and students involved in the second year of the study.

\section{Impact on the university}

Our partnership offers a response to Healey's (2018) call for student-faculty partnerships to contribute as change agents for teaching and learning in higher education. As we previously discussed, our design-based research study focused on improving teaching and learning within a course that serves over 500 undergraduate students. Additionally, our research offered professional learning for instructors by building their capacity for collaborative instructional design. Furthermore, we have disseminated the findings of our study and our model for student-faculty partnership to a variety of audiences through conference presentations and academic journal publications. 


\section{NEXT STEPS AND FURTHER INQUIRY}

We are excited by the potential of student-faculty partnerships within design-based research and have many questions we intend to pursue through future inquiry. In the second year of our SoTL study, we will further document the impact of our partnership on teaching and learning. Additionally, we plan to document our experiences of partnership and the norms and tools we use to support co-production. In particular, we are interested in exploring how design thinking collaborative processes, like the ones we used with our instructor team, can support knowledge building within a student-faculty partnership. Beyond this study, we see potential in developing a model for student-faculty partnership in a design-based research study drawing on collective leadership practices. We are also interested in how our experience might be taken up by other teams and be employed to support teaching and learning in other courses. We see potential for this model to be used as a strategy by course coordinators or other instructional leaders to build collective leadership capacity within instructor teams.

\section{NOTE ON CONTRIBUTORS}

Joshua Hill is a PhD candidate and sessional instructor at the Werklund School of Education at the University of Calgary. In his doctoral research he is exploring how school system leaders can practice design to occasion the emergence and nurture the development of a robust and productive learning system.

Dr. Christy Thomas is an instructor in graduate and undergraduate at the Werklund School of Education. Dr. Thomas' research focuses on teaching and learning. Within this focus, her research interests include professional learning, leadership, collaboration, and research-practice partnerships.

Dr. Barbara Brown is director of professional graduate programs and partner research schools in the Werklund School of Education at the University of Calgary. Her current research interests include research-practice partnerships, professional learning, and collaborative instructional design in technology-enhanced learning environments.

Note: Support for this research was provided through a Scholarship of Teaching and Learning Grant from the University of Calgary (Grant \#10018404)

\section{REFERENCES}

Barab, S., \& Squire, K. (2004). Design-based research: Putting a stake in the ground. Journal of the Learning Sciences, 13(1), 1-14. https://doi.org/10.1207/s15327809jls1301 1

Berg, M., \& Seeber, B. K. (2017). Slow professor: Challenging the culture of speed in the academy. Toronto, Canada: University of Toronto Press. https://doi.org/10.3138/9781442663091 
Brown, B., Hartwell, A., \& Thomas, C. (2018). Interdisciplinary design teams of pre-service and in-service teachers: Issues with collaboration. Canadian Journal of Action Research, 19(1), 3-21.

Brown, B., \& Jacobsen, M. (2016). Principals' technology leadership: How a conceptual framework shaped a mixed methods study. Journal of School Leadership, 26(5), 811-836. https://doi.org/10.1177/105268461602600504

Brown, B., Thomas, C., Hill, J., Alonso-Yanez, G. (2019). Fostering collaborative learning in an undergraduate interdisciplinary education course. Teaching and Teacher Education, Division K - Section 5, American Educational Research Association (AERA), April 5-9, 2019, Toronto, ON. http://hdl.handle.net/1880/110379

Cliffe, A., Cook-Sather, A., Healey, M., Healey, R., Marquis, E., Matthews, K. E., MercerMapstone, L., Ntem, A., Puri, V., \& Woolmer, C. (2017). Launching a journal about and through Students as Partners. International Journal for Students as Partners, 1(1) 1-9. https://doi.org/10.15173/ijsap.v1i1.3194

Cook-Sather, A. (2014). Student-faculty partnership in explorations of pedagogical practice: A threshold concept in academic development. International Journal for Academic Development, 19(3), 186-198. https://doi.org/10.1080/1360144X.2013.805694

Cook-Sather, A., Bovill, C., \& Felten, P. (2014). Engaging students as partners in learning and teaching: A guide for faculty. San Francisco, CA: Jossey-Bass.

Haraway, D. (1988). Situated knowledges: The science question in feminism and the privilege of partial perspective. Feminist Studies, 14(3), 575-599. http://doi.org/10.2307/3178066

Harris, A., \& Muijs, D. (2004). Distributed leadership. In Improving Schools through Teacher Leadership (pp. 27-36). Berkshire, UK: Open University Press.

Healey, M. (2018). Students as partners and change agents in learning and teaching in higher education. Retrieved from http://www.mickhealey.co.uk/resources

Hill, J.T., Thomas, C., \& Brown, B. (2018) Hacking for collaboration towards redesigning group work. University of Calgary Conference on Postsecondary Learning and Teaching, May 12, Calgary, AB http://dx.doi.org/10.11575/PRISM/32849

Kennedy, A., Deuel, A., Nelson, T., \& Slavit, D. (2011). Requiring collaboration or distributing leadership? Phi Delta Kappan, 92(6), 20-24. https://doi.org/10.1177/003172171109200805

McCulloch, A. (2009). The student as co-producer: Learning from public administration about the student-university relationship. Studies in Higher Education, 34(2), 171-183. https://doi.org/10.1080/03075070802562857

McKenney, S., \& Reeves, T. C. (2012). Conducting educational design research. New York, NY: Routledge. https://doi.org/10.4324/9780203818183

Mercer-Mapstone, L., Dvorakova, S. L., Matthews, K., Abbot, S., Cheng, B., Felten, P., Knorr, K., Marquis, E., Shammas, R., \& Swaim, K. (2017). A systematic literature review of Students as Partners in higher education. International Journal for Students as Partners, 1(1). 1-23. https://doi.org/10.15173/ijsap.v1i1.3119

Merriam, S. B. (2008). Third update on adult learning theory. San Francisco, CA: Jossey-Bass. 
Neary, M., \& Winn, J. (2009). The student as producer: reinventing the student experience in higher education. In: The future of higher education: policy, pedagogy and the student experience. (pp. 192-210). London: Continuum

Miles, M., Huberman, A., \& Saldana, J. (2014). Qualitative data analysis: a methods sourcebook ( $3^{\text {rd }}$ ed.). Thousand Oakes, CA: Sage.

Scardamalia, M., \& Bereiter, C. (2003). Knowledge building environments: Extending the limits of the possible in education and knowledge work. In A. DiStefano, K. E. Rudestam, \& R. Silverman (Eds.), Encyclopedia of distributed learning (pp. 269- 272). Thousand Oaks, CA: Sage Publications. Retrieved from http://www.ikit.org/fulltext/2003 KBE.pdf

Scardamalia, M., \& Bereiter, C. (2006). Knowledge building: Theory, pedagogy, and technology. In R. K. Sawyer (Ed.), The Cambridge Handbook of the Learning Sciences (pp. 97-115). New York, NY: Cambridge University Press. https://doi.org/10.1017/CB09780511816833.008

Thomas, C. (2016). Exploring the impact of professional development partnerships on teaching and learning (Doctoral dissertation). Retrieved from https://prism.ucalgary.ca/handle/11023/2871

Thomas, C., Brown, B., \& Hill, J. (2019) Technology for pre-service teacher collaboration. Canadian Society for the Study of Education (CSSE), June 2-5, University of British Columbia, BC.

Wang, F., \& Hannafin, M. (2005). Design-based research and technology-enhanced learning environments. Educational Technology Research and Development, 53(4), 5-23. https://doi.org/10.1007/BF02504682 